\title{
Screening of Brassica germplasm against Albugo candida (White rust disease) on Brassica species (Rapeseed-mustard)
}

\author{
K.S. Bisht*, A.K. Tewari and Pooja Upadhyay \\ - 263 145, U.S. Nagar (Uttarakhand), INDIA \\ *Corresponding author. E-mail: ksbisht1972@gmail.com \\ Received: August 31, 2015; Revised received: January 21, 2016; Accepted: April 23, 2016
}

Centre of Advance studies, Department of Plant Pathology, College of Agriculture, GBPUA\&T, Pantnagar

\begin{abstract}
White rust distributed worldwide, caused by Albugo candida (Pers. Ex. Lev.) Kuntze. (A. Cruciferarum S. F. Gray) is one of the major disease responsible in reducing the yield of rapeseed-mustard. Among various management approaches use of resistant varities is consider best, as it is cost effective and environment friendly. However, till now only few resistant sources against the disease has been reported. Therefore, in the present investigation 70 rapeseed-mustard germplasm have been evaluated in field under epiphytotic conditions during 2011-12 and 2012-13 crop seasons. All the germplasms showed similar disease reaction after screening in both the years. Among 70 germplasm, seven germpalsms i.e. DLDC-1, DRMR-100, DRMR-312, EC-339000, GSL-1, NPJ-158 and RH-0644 were found free from the disease with $0 \%$ disease severity. These germplasms could be used in breeding programmes for the development of resistant genotypes having high yield potential.
\end{abstract}

Keywords: Albugo candida, Pathogen, Resistance, Rapeseed-mustard, Screening

\section{INTRODUCTION}

White rust disease is a major disease of Brassica species (Rapeseed-mustard) appears in different proportions on rapeseed-mustard crops in several localities throughout the world. (Saharan and verma, 1992). The disease has been recorded from more than eight countries of the world with a host range of more than 300 hosts (Meena, et al., 2014). White rust infection on plants resulted from two types 'local and systemic' (Verma and Petrie, 1980). In systemic infection disease appears as distortion, hypertrophy, hyperplasia and sterility of inflorescence. This phase of infection has been referred as the staghead (Maheshwari et al., 1985; Kolte, 1985 and Awasthi et al., 1995).

White rust disease cause intensive yield losses. In India a yield loss of 17-32 percent in B. juncea and $B$. rapa (Bains and Jhooty, 1979) 23-55 per cent (Saharan et al. 1984), 31.5-37.2 per cent (Sing et al. 1990), 20-60 per cent (Bisht et al., 1994) and 17-34 per cent (Gupta et al., 2004) has been reported. Kolte et al. (1986) reported yield loss of 17-32 per cent in $B$. juncea in India, due to mixed infection of $A$. candida and Hyaloperonospora brassicae. Presently the growers are mainly dependent on chemical fungicides for the partial management of the disease which is not ecofriendly. To overcome these problems the only alternative method is to search out resistant sources from the available Brassica germplasm for the development of high yielding resistant varieties against the disease. Keeping above in view the present investiga- tion was carried out for screening the Brassica germplasm against white rust disease.

\section{MATERIALS AND METHODS}

The experiment was conducted at Norman E. Borlaug Crop Research Centre, G.B. Pant University of Agriculture and Technology, Pantnagar, Uttarakhand, during rabi crop season of year 2011-12 and 2012-2013 for screening of white rust disease of rapeseedmustard. Brassica germplasm supplied by DRMR, Sewar, Bharatpur, Rajasthan (Table 1). These germplasm of rapeseed mustard were used for determining their phenotypic disease reactions against white rust under artificially inoculated conditions for selection of resistant sources. Each entry was sown in two rows each of $3 \mathrm{~m}$ length with two replications. Line to line distance was $30 \mathrm{~cm}$, while plant to plant distance was $10-15 \mathrm{~cm}$. PYS 6 was sown as a susceptible check after each entry. Each test entry and susceptible checks were artificially inoculated with white rust inoculum.

Methods of inoculation: Oosporic material i.e. staghead source of primary inoculum, collected from the previous year crop were grinded, mixed with the seeds before sowing and applied into the soil along with the seed at the time of sowing which served as source of primary inoculum in causing infection.

Fresh infected leaves contained white rust pustules which served as secondary source of inoculum were collected and made sporangial suspension in distilled water. Inoculum concentration was adjusted to $10^{4}$ 





sporangia/ ml using haemocytometer. Prepared sporangial suspension of $A$. candida was sprayed directly to test plants at cotyledonary stage (2/3 leaf stage) and at initiation of flowering stage in the evening. Irrigation was done just after spraying and regular spraying of tab water as per requirement to maintain optimum $\mathrm{RH}$ and moisture for 3 days after inoculation. Crop after spraying was regularly watched for appearance of the disease. The observations on disease severity and disease reaction was recorded on the basis of all leaves on 10 plants selected randomly from each germplasm at maximum disease pressure i.e. at 75 DAS. using 0-9 rating scale (Table 2) as given in AICRP R\&M (2010).

Table 2. Rating (0-9) scale for measuring disease severity and disease reaction (AICRP R\&M, 2010).

\begin{tabular}{lll} 
Rating score & Leaf area covered $(\%)$ & Disease reaction \\
\hline 0 & No symptoms & Immune \\
\hline 1 & $<5$ & Highly resistant \\
3 & $6-10$ & Resistant \\
5 & $11-25$ & Moderately \\
& & Resistant \\
7 & $26-50$ & Susceptible \\
9 & $<50$ & Highly \\
& & susceptible \\
\hline
\end{tabular}

\section{RESULTS AND DISCUSSION}

In the present investigation, out of seventy germplasm (70) seven germplasm i.e. DLDC-1, DRMR-100, DRMR-312, EC-339000, GSL-1, NPJ-158 and RH0644 showed immune reaction i.e. free from the disease. EC-414299, PT-303, TK-17-14, YSB-9 and DRMRIJ-11-287 were moderately resistant with a disease severity of 11.11-16.67 per cent, RMM-09-10, RMT-08-06, RMT-08-2, TKM 10-2, Divya-33, DRMRIJ-11-286, JMM-07-1，DRMR-261，JMT-0813, NPJ-121, NPJ-127, NRCDR-705 and PAB-200516 were susceptible with a disease severity 26-50 per cent while, DRMR-11-10, DRMR-11-11, DRMRIJ-11 -275, DRMRIJ-31, CJ-37-61, DRMR-11-08, DRMR11-09, EC-414322, EC-414324, JMM 07-2, JMM-081, JMWR-08-3, LES-42, LES-43, LET-36, NDRE-7, NDYR-32, NPJ-140, NPJ-151, NPJ-152, NPJ-157, NPJ-164, NPJ-165, NPJ-166, NPJ-167, PAB-2004-4, PBR-375, PRE-2007-6, PRKS-28, RAUDL-9-32, RAURD-09-212, RAURDL-02-01, RGN-282, RH0704, RH-0735, RH-0749, RH-0834, RH-0904, RMWR-09-5, ROHINI, SKM-815, SKM-B-817 and Varuna were found highly susceptible with more than 50 per cent against white rust (Table 3). Yadav et al. (1999). evaluated 74 Indian mustard (Brassica juncea) germplasm lines for resistance against white rust diseases. None of the genotype was found resistant $\mathrm{Li}$ et al. (2007). Screened 44 B. juncea genotypes, viz. 22 from India, 12 from Australia, and 10 from China, Out of 40 genotypes, 04 Chinese genotypes (CBJ-001, CBJ-002, CBJ-003, CBJ-004) and 01 Australian genotype (JR049) consistently showed high resistance to $A$. candida. Li et al. (2008). who screened 44 B. juncea genotypes among them CBJ-001, CBJ-003 and CBJ-004 showed highly resistance against $A$. candida. Meena et al. (2011) reported PBC 9221, and EC 414299 brassica lines as resistant to white rust. DRMR (2011) reported EC414291, EC 414293, MCB1, DRMR 243, DRMR 261, DRMR 270, NRCDR 705, JMWR 945-2-2-75 Kr, EC 399313, JYM 11 and NDWR 5-1 as resistant lines to white rust. In earlier studies different workers evaluated different Brassica germplasms and reported few germplasms as a resistant source. However, in the present investigation Brassica lines tasted were different from earliar workers. In the present studies few lines were found free from the disease, however some lines were found moderately resistant.

\section{Conclusion}

In this study, seventy germplasms of $B$. carinata, $B$. napus, B. juncea, and B. rapa were screened out against white rust disease. Among these DLDC-1, DRMR-100 \& DRMR-312 (B.carinata); EC-339000 \& GSL-1 (B. napus); NPJ-158 \& RH- 0644 (B. juncea) were free from the disease with $0 \%$ disease severity. The NPJ-158 and RH-0644 (B.juncea) lines could be best exploited as a source of resistance in breeding programme for the development of high yielding varities against white rust disease.

\section{REFERENCES}

AICRP R\&M. (2010). Annual progress report. All India Coordinated Research Project on Rapeseed-Mustard., Bharatpur. India.

Awasthi, R.P. Nashaat, N.I. and Kolte. S.J. (1995). Interaction between Peronospora parasitica and Albugo candida in relation to staghead formation in B. juncea. In; National symposium on "Detection of plant pathogens and their management". IPS. 18-20 Jan., Faizabad, UP, India $36 \mathrm{p}$

Bains, S.S. and Jhooty, J.S. (1979). Mixed infection of $\mathrm{Al}$ bugo candida and Peronospora parasitica on Brassica juncea inflorescence and their control. Indian Phytopathology, 32: $268-271$.

Bisht, I.S., Agrawal, R.C. and Singh, R. (1994). White rust (Albugo candida) severity in mustard (B. juncea) varieties and its effects on seed yield. Pant Variety and Seed, 7: $85-89$.

DRMR. (2011). Annual progress report. All India Coordinated Research Project on Rapeseed-Mustard., Bharatpur. India.

Gupta, K., Prem, D. and Agnihotri, A. (2004). Role of biotechnology for incorporating white rust resistance in Brassica species. Plant Biotechnology and Molecular Markers. Anamaya Publisher, New Delhi, India

Kolte, S.J., Awasthi, R.P. and Vishwanath (1985). Field performance of improved toria (Brassica campestris var. toria) varities against Alternaria blight, downy mildew and white rust diseases. Indian Journal of Mycology and Plant Patholology, 15(2): 211-213.

Kolte, S.J., Awasthi, R.P. and Vishwanath (1986). Effect of planting dates and associated weather factors on stag- 
Table 1. Screening of Brassica germplasm for white rust disease resistance.

\begin{tabular}{|c|c|c|c|c|c|}
\hline \multirow{2}{*}{$\begin{array}{l}\text { Rating scale (0-9) } \\
\text { Per-cent intensity }\end{array}$} & \multirow{2}{*}{ Reaction } & \multirow[b]{2}{*}{ Germplasm } & \multicolumn{3}{|c|}{ Disease reaction of white rust on the basis of disease severity } \\
\hline & & & No. of Germplasm & \%Disease severity & Disease* reaction \\
\hline \multirow{7}{*}{$0 \%$} & \multirow{7}{*}{ Immune } & \multirow{7}{*}{07} & DLDC-1 & 0.00 & Immune \\
\hline & & & DRMR-100 & 0.00 & Immune \\
\hline & & & DRMR-312 & 0.00 & Immune \\
\hline & & & EC-339000 & 0.00 & Immune \\
\hline & & & GSL-1 & 0.00 & Immune \\
\hline & & & NPJ-158 & 0.00 & Immune \\
\hline & & & RH-0644 & 0.00 & Immune \\
\hline$>5 \%$ & Highly resistant & 00 & Nil & - & - \\
\hline \multirow[t]{3}{*}{$5-10 \%$} & \multirow[t]{2}{*}{ Resistant } & 00 & Nil & - & - \\
\hline & & & EC-414299 & 16.67 & Moderately resistant \\
\hline & & & PT-303 & 16.67 & Moderately resistant \\
\hline $11-25 \%$ & Moderately & 05 & TK-17-14 & 16.67 & Moderately resistant \\
\hline & & & YSB-9 & 16.67 & Moderately resistant \\
\hline & & & DRMRIJ-11-287 & 11.11 & Moderately resistant \\
\hline & & & RMM-09-10 & 50.00 & Susceptible \\
\hline & & & RMT-08-06 & 38.89 & Susceptible \\
\hline & & & RMT-08-2 & 38.89 & Susceptible \\
\hline & & & TKM-10-2 & 47.22 & Susceptible \\
\hline & & & Divya-33 & 47.22 & Susceptible \\
\hline & & & DRMRIJ-11-286 & 50.00 & Susceptible \\
\hline & & & JMM-07-1 & 50.00 & Susceptible \\
\hline $26-50 \%$ & Susceptible & 14 & DRMR-261 & 44.44 & Susceptible \\
\hline & & & JMT-08-13 & 36.11 & Susceptible \\
\hline & & & NPJ-121 & 50.00 & Susceptible \\
\hline & & & NPJ-127 & 50.00 & Susceptible \\
\hline & & & NRCDR-705 & 47.22 & Susceptible \\
\hline & & & PAB-2005-16 & 44.44 & Susceptible \\
\hline & & & PBR-378 & 44.44 & Susceptible \\
\hline & & & DRMR-11-10 & 66.66 & Highly susceptible \\
\hline & & & DRMR-11-11 & 72.22 & Highly susceptible \\
\hline & & & DRMRIJ-11-275 & 77.77 & Highly susceptible \\
\hline & & & DRMRIJ-31 & 77.77 & Highly susceptible \\
\hline & & & CJ-37-61 & 61.11 & Highly susceptible \\
\hline & & & DRMR-11-08 & 72.22 & Highly susceptible \\
\hline & & & DRMR-11-09 & 58.33 & Highly susceptible \\
\hline & & & EC-414322 & 61.11 & Highly susceptible \\
\hline & & & EC-414324 & 61.11 & Highly susceptible \\
\hline & & & JMM-07-2 & 61.11 & Highly susceptible \\
\hline & & & JMM-08-1 & 77.77 & Highly susceptible \\
\hline & & & JMWR-08-3 & 55.55 & Highly susceptible \\
\hline & & & JYM-11 & 66.66 & Highly susceptible \\
\hline & & & LES-42 & 58.33 & Highly susceptible \\
\hline & & & LES-43 & 58.33 & Highly susceptible \\
\hline & & & LET-36 & 69.44 & Highly susceptible \\
\hline & & & NDRE-7 & 58.33 & Highly susceptible \\
\hline & & & NDYR-32 & 72.22 & Highly susceptible \\
\hline & & & NPJ-140 & 74.99 & Highly susceptible \\
\hline & & & NPJ-151 & 77.77 & Highly susceptible \\
\hline & & & NPJ-152 & 80.55 & Highly susceptible \\
\hline 500 & Highly & & NPJ-157 & 69.44 & Highly susceptible \\
\hline$<50 \%$ & Susceptible & 44 & NPJ-164 & 77.77 & Highly susceptible \\
\hline & & & NPJ-165 & 77.77 & Highly susceptible \\
\hline & & & NPJ-166 & 72.22 & Highly susceptible \\
\hline & & & NPJ-167 & 74.99 & Highly susceptible \\
\hline & & & PAB-2004-4 & 61.11 & Highly susceptible \\
\hline & & & PBR-375 & 58.33 & Highly susceptible \\
\hline & & & PRE-2007-6 & 66.66 & Highly susceptible \\
\hline & & & PRKS-28 & 72.22 & Highly susceptible \\
\hline & & & RAUDL-9-32 & 61.11 & Highly susceptible \\
\hline & & & RAURD-09-212 & 77.77 & Highly susceptible \\
\hline & & & RAURDL-02-01 & 69.44 & Highly susceptible \\
\hline & & & RGN-282 & 66.66 & Highly susceptible \\
\hline & & & RH-0704 & 63.88 & Highly susceptible \\
\hline & & & RH-0735 & 77.77 & Highly susceptible \\
\hline & & & RH-0749 & 55.55 & Highly susceptible \\
\hline & & & RH-0834 & 61.11 & Highly susceptible \\
\hline & & & RH-0904 & 77.77 & Highly susceptible \\
\hline & & & RM-WR-09-5 & 66.66 & Highly susceptible \\
\hline & & & ROHINI & 61.11 & Highly susceptible \\
\hline & & & SKM-815 & 55.55 & Highly susceptible \\
\hline & & & SKM-B-817 & 55.55 & Highly susceptible \\
\hline & & & Varuna & 77.77 & Highly susceptible \\
\hline
\end{tabular}


head phase of white rust and downy mildew of rapeseed and mustard. Indian Journal of Mycology and Plant Patholology, 10 (2): 94-102.

Li, C.X., Sivasithamparam, K., Walton, G., Fels, P., Barbetti, M.J. (2008). Both incidence and severity of white rust disease reflect host resistance in Brassica juncea germplasm from Australia, China and India, Field Crops Res, 106(1): 1-8.

Li, C.X., Sivasithamparam, K., Walton, G., Salisbury P., Burton, W., Banga, Surinder, Banga, S.S., Shashi, Chattopadhyay, C., Kumar, A., Singh, R., Singh, D., Agnohotri, A., Liu, S.Y., Li Y.C., Fu T. D., Wang, Y.F. and Barbetti, M.J. (2007). Expression and relationships of resistance to white rust (Albugo candida) at cotyledonary, seedling, and flowering stages in Brassica juncea germplasm from Australia, China, and India: Australian Journal of Agricultural Research, 58(3): 259-264.

Maheshwari, D.K., Chaturvedi, S.N. and Yadav, B.S. (1985). Structure and development of galls induced by Albugo in inflorescence axis of Brassica juncea. Indian Phytopathology, 38: 546-548.

Meena, P.D., Awasthi, R.P., Godika, S., Gupta, J.C., Kumar, A., Sandhu, P.S., Sharma, P., Rai, P.K., Singh, Y.P., Rathi, A.S., Prasad, R., Rai, D. and Kolte, S.J. (2011). Eco-friendly approaches managing major diseases of
Indian mustard. World Applied Science. Journal, 12 (8):1192-1195

Meena, P.D., Verma, P.R., Saharan, G.S. and Borhan, M.H. (2014). Historical perspectives of white rust caused by Albugo candida in Oilseed Brassica. Journal of Oilseed Brassica, 5: 1-41.

Saharan, G.S., Kaushik, C.D., Gupta, P.P. and Tripathi, N.N. (1984). Assessment of losses and control of white rust of mustard. Indian Phytopathology, 37: 397.

Saharan, G.S. and Verma, P.R. (1992). White rust: A review of economically important species. International Development Research Centre, Ottawa. Ontario, Canada, IDRC-MR315e, IV+65p.

Singh, B.M., Sharma, B.M. and Kapoor, A.S. (1990). Costus a new host record for white rust and downy mildew from India. Indian Phytopathology, 43(2): 237-238.

Verma, P.R. and Petrie, G.A. (1980). Effect of seed infestation and flower bud inoculation on systemic infection of turnip rape by Albugo candida. Can Journal of Plant Science. 60: 267-271

Yadav, M.S., Dhillon, S.S., Kaur, S., Brar, K.S. and Singh, K. (1999). Screening of Indian mustard germplasm for resistance to Alternaria blight and white rust. Plant Disease Research, 14(1): 70-72. 